\title{
1999: LA MASACRE DE EL PLACER \\ O EL PROBLEMA POLÍTICO DE LA MEMORIA Y EL PERDÓN
}

JOHAN CAMILO SÁNCHEZ MEDINA

Universidad del Rosario, Colombia

(c) 


\title{
1999: LA MASACRE DE EL PLACER O EL PROBLEMA POLÍTICO DE LA MEMORIA Y EL PERDÓN`
}

\begin{abstract}
Resumen: el presente ensayo pretende hacer un análisis crítico sobre el régimen de dominio paramilitar del que fue víctima la población de El Placer durante el periodo que va desde 1999 hasta el 2006. El trabajo tiene dos objetivos fundamentales. El primero es hacer uso de algunos testimonios de los sobrevivientes para ofrecer un panorama general del contexto hostil en el que vivió la población. De ahí se pretende resaltar, especialmente, el daño y los ejercicios de perpetración sobre las mujeres. El segundo objetivo es problematizar el tema de la memoria, de la política y del perdón en Colombia a través de la noción del diferendo (différend), concepto ya propuesto y desarrollado por el filósofo francés Jean F. Lyotard. Mi impresión es que, desde este punto de vista, se puede cuestionar (i) la falta de participación del Estado colombiano en escenarios del conflicto armado, y (ii) las soluciones que, por medio del derecho y del modelo de justicia transicional de la época, se proponen para dar solución a los daños de las víctimas. Más que aventurar una hipótesis, el texto constituye una tentativa por abordar un problema más bien recurrente en las actuales discusiones académicas en Colombia, a saber: ¿cómo lidiar con la reconciliación entre las víctimas y los victimarios donde lo que prima es el reconocimiento de un daño que, en principio, resulta imperdonable?
\end{abstract}

Palabras claves: Memoria, política, perdón, justicia transicional y diferendo.

\section{9: THE SLAUGTHER OF THE EL PLACER OR THE POLITICAL PROBLEM OF THE MEMORY AND THE FORGIVENESS}

\begin{abstract}
This paper attempts to analyze the case of the regime paramilitary which was victim the community of El Placer between 1999 and 2006. This essay has two main objectives. The first is to use some testimonies of the survivors to provide an overview of the hostile environment in which the population lived. Here, I pretend to emphasize, especially, the harm and the perpetration on the women. The second objective is to analyze the Colombian problem of the memory, the politics and the forgiveness through the notion of the differend (différend), concept proposed and developed by the philosopher Jean F. Lyotard. My impression is that, from this point of view, we can criticize (i) the lack of participation of the Colombian State in the armed conflict places, and (ii) the solutions that, through of the law and the model of transitional justice of this period, were propose to solve the harm of the victims. More than venture a thesis, this text is an attempt to approach a rather recurring problem in the current academics discussions in Colombia: How to deal with the problem of the reconciliation between the victims and the victimizers where what prevails is the recognition of a harm that, in principle, is unforgivable?
\end{abstract}

Keywords: Memory, politics, forgiveness, transitional justice and differend.

Fecha de recepción: abril 14 de 2016

Fecha de aceptación: julio 28 de 2016

Forma de citar (APA): Sánchez, J. (2017). 1999: la masacre de El placer el problema político de la memoria y el perdón. Revista Filosofía UIS. 16 (1), doi: http://dx.doi.org/10.18273/revfil.v16n1-2017003

Forma de citar (Harvard): Sánchez, J. (2017). 1999: la masacre de El placer el problema político de la memoria y el perdón. Revista Filosofía UIS. 16 (1), 49-77.

Johan Camilo Sánchez: colombiano. Filósofo de la Universidad del Rosario.

Correo electrónico: johan.sanchez@urosario.edu.co

\footnotetext{
* Artículo de reflexión
} 


\section{9: LA MASACRE DE EL PLACER O EL PROBLEMA POLÍTICO DE LA MEMORIA Y EL PERDÓN'}

\section{Preámbulo}

Entre 1980 y el 2006, gran parte de la población del Sur del Putumayo se vio azotada por el ya conocido conflicto armado que sostuvieron grupos guerrilleros y paramilitares en la zona. Lastimosamente, las consecuencias de estos enfrentamientos dejaron tras de sí centenares de víctimas, sin contar la cantidad de crímenes de lesa humanidad que se cometieron en materia de secuestro, extorsión, desplazamiento forzado, masacre y genocidio. Resumamos a modo de introducción las características del problema.

En 1991 el Frente 48 de las FARC logra establecer un centro de control en el casco urbano de la población de El Placer, donde se radican como autoridad política y se presentan como amigos del pueblo, es decir, ofreciendo apoyo en temas de seguridad territorial y prevención de la desigualdad campesina. De este modo, tejen lazos de familiaridad y demarcan funciones y deberes dentro de la comunidad. Sin embargo, poco después de haber ganado confianza y de haber afianzado normas de comportamiento, las figuras individuales de los actores armados terminan por gozar y ejercer un poder que les da el derecho, entre otras cosas, de abusar en el control de la economía y de exigir al hacendado o al campesino la famosa "vacuna" (una especie de impuesto que era cobrado con el pretexto de garantizar la seguridad del municipio). Como es de esperar, estas condiciones repercutieron negativamente sobre las condiciones de vida de la población, pues el tejido social que se fue configurando entre el pueblo y la guerrilla resultó ser un agravante más para que, posteriormente, las autodefensas

1 Este texto es resultado de uno de los seminarios que fueron impartidos dentro del proyecto del grupo de investigación Identidades Narrativas y Sufrimiento en la Universidad del Rosario. El proyecto ha contado con el respaldo de Colciencias y actualmente está a cargo de Wilson Herrera Romero, doctor en filosofía y profesor titular de la Escuela de Ciencias Humanas. 
(AUC) ejercieran todo tipo de vejaciones sobre la integridad física y moral de los habitantes.

Así, a partir de 1999, y tras una larga disputa por el territorio, el Bloque Sur del Putumayo de las autodefensas logra tomarse el control del municipio, en lo que los especialistas han decidido llamar la masacre del 7 de noviembre de El Placer. ${ }^{2}$

Claramente, la incursión de las autodefensas (AUC) está fuertemente motivaba por intereses económicos y políticos. Pero como se ha vuelto costumbre en las características del conflicto armado en Colombia, a dicho grupo los motiva un objetivo militar que básicamente consiste en ganar la guerra y apoderarse de la tierra. Así que el objetivo paramilitar consiste en desalojar y desaparecer cualquier tipo de influencia guerrillera de la zona. Por eso, y en vista de los lazos de "familiaridad" con la guerrilla, los habitantes se convierten en enemigos potenciales de las autodefensas. Aunque, al final, es sobre la comunidad que recaen las consecuencias del conflicto. Asimismo, después de controlar militarmente el casco urbano del municipio, igualmente se tornan permisivos con el abuso del poder individual sobre la población. En este sentido, la lógica de control se puede resumir en los siguientes términos: si alguien es o tiene nexos guerrilleros, se le asesina, se le expropia o se le destierra; si no, entonces queda supeditado a las normas y a la forma de gobierno que decrete la autoridad política del jefe paramilitar.

Pero no solo se trata de eso. El trasfondo de este conflicto armado también tiene un componente político y económico, dentro del cual el tema del narcotráfico no es ajeno al fenómeno. Lo cierto es que el negocio de la producción y de la distribución de las drogas resulta ser un aspecto determinante en el desarrollo del conflicto, ya que muchos de los intereses por el control del territorio están ligados a la posibilidad de administrar el crecimiento de los cultivos ilícitos alrededor del municipio, a fin de financiar la guerra y sus respectivas acciones bélicas. De modo que, así como el control territorial es importante dentro de la estrategia militar, el narcotráfico se convierte igualmente en el remanente indispensable de la guerra ${ }^{3}$.

\footnotetext{
${ }^{2}$ Por especialistas me refiero a gran parte de los investigadores del Centro de Memoria Histórica que se han encargado de hacer un trabajo minucioso, histórico y etnográfico, sobre el tema de las masacres y la recopilación de testimonios de las víctimas, sin contar el análisis sobre las condiciones de vulnerabilidad de las poblaciones, en cierto modo, olvidadas por el Estado.

${ }^{3}$ Con 'economía de la guerra' quiero resaltar la dinámica del proyecto político paramilitar, pues si se le concibe como tal, es decir, como un proyecto político, entonces la economía del narcotráfico es una expresión de ello, debido a que los ingresos están destinados primordialmente a financiar las acciones bélicas producidas dentro del conflicto armado.
} 
En este orden de ideas, un aliciente más de este conflicto interno es la marcada condición de vulnerabilidad de la población por causa de la falta de seguridad estatal. En sentido estricto, durante este tiempo los habitantes de El Placer quedan a merced, o bien quedan sometidos a un régimen de gobierno insurgente $y$ subversivo, dentro de los lineamientos de un proyecto político y económico claramente ilegal, que opera en ausencia del Estado, es decir, que opera por fuera de los estamentos jurídicos de la ley y de la seguridad democrática.

Ahora bien, una vez descrito el contexto e imbuido de esta problemática política, el presente ensayo pretende hacer un análisis conceptual sobre las condiciones a las que fueron sometidos los habitantes de El Placer durante los siete años de dominio paramilitar (1999-2006). De manera que lo realmente importante es mostrar el proceso de victimización dentro de esta lógica de organización de las autodefensas, a fin de darle sentido a la pregunta que guía el presente ensayo: ¿cómo lidiar con la reconciliación entre las víctimas y los victimarios donde lo que prima es el reconocimiento de un daño que, en principio, resulta imperdonable?

Pues bien, para cumplir con dicho objetivo, considero conveniente adoptar dos perspectivas metodológicas: una descriptiva y otra conceptual.

1. Por un lado, se hará una descripción, si no detallada, sí por lo menos que destaque las condiciones de vida de la comunidad en ese contexto. En esta primera aproximación el objetivo es mostrar los mecanismos de intimidación y de estigmatización que recaen sobre los individuos de la comunidad, tratando de resaltar, especialmente, los vejámenes cometidos sobre las mujeres. Pero no solo eso. De esta manera, también se analizará la incidencia del narcotráfico en el modelo de organización paramilitar y las características de lo que, por ahora, me atrevo a llamar un gobierno paraestatal. Así que, en términos generales, la idea es ofrecer un panorama local de la guerra y de sus respectivas consecuencias, pero a condición de responder o de trabajar alrededor de la pregunta de investigación.

Para ello, igualmente considero de vital importancia seguir cuidadosamente el informe del Centro Nacional de Memoria Histórica (CNMH) hecho en el 2012. En este documento hay una recopilación valiosa de los testimonios de las víctimas que describen con precisión la hostilidad y los vejámenes a los que se vieron sometidos los habitantes y, en especial, las mujeres del municipio durante dicha época. El documento, además, hace una reconstrucción juiciosa del problema del narcotráfico y de los antecedentes del conflicto armado entre la guerrilla y los paramilitares, y logra poner en entredicho el proceso de desmovilización de las autodefensas y las políticas implementadas por el gobierno de Álvaro Uribe en contra del narcotráfico y la guerrilla, en la medida que crítica la ausencia del Estado, si no en la mayoría, sí por lo menos en gran parte del departamento del Putumayo. 
2. Por otro lado, aunque de manera simultánea, la tarea es realizar un análisis conceptual del caso en cuestión. Se trata, entre otras cosas, de darle consistencia al tratamiento de los testimonios, porque si bien hay un trabajo exhaustivo del informe por dar voz a aquellos que han sido callados, sigue latente el problema de cómo hacer memoria, de cómo comprender la magnitud del daño de aquellas víctimas que aún no han podido dar su testimonio. Y la dificultad estriba en que, al menos en este caso, hay un proceso de deshumanización que, en un contexto social más amplio, lastimosamente resulta ignorado, rechazado, silenciado. Justo de allí surge el problema de investigación del presente ensayo, a saber: ¿cómo reconciliar, cómo reparar y cómo hacer memoria entre víctimas y victimarios?

En vista de este interrogante, y aunque parece complicado disponer de un sistema de comprensión total del problema, al menos en ente caso la filosofía sí nos ofrece un conjunto de herramientas conceptuales para hacerle frente. En este sentido, considero que el concepto diferendo, propuesto por el filósofo francés Jean F. Lyotard (1999), hace justicia o, al menos, nos puede dar luces acerca de la inexistencia del reconocimiento jurídico y político de los testimonios de las víctimas. Grosso modo, un diferendo se presenta cuando en un contexto de conflicto "lo que está sujeto a la amenaza no es un individuo identificable sino que es la capacidad de hablar y de callarse" de una comunidad. Esto no quiere decir, sin embargo, que la amenaza afecte en general al conjunto de la población. Quiero decir: hay casos individuales que requieren ser trabajados por separado. Pero lo cierto, y eso es lo interesante del concepto, es que hay casos especiales en los que la dimensión individuo/comunidad resultan indiscernibles, pues la amenaza se puede presentar en dos sentidos: o bien porque le es imposible hablar a un individuo en particular, o bien porque es imposible expresar un daño dentro de la comunidad (Lyotard, 1999, p: 234); al final, ambas opciones pueden destruirse por medio del asesinato.

Una cosa más: desde este punto de vista, se pueden identificar tres ejes transversales que atraviesan el presente problema: (i) la expansión de los cultivos ilícitos y el desarrollo de la economía del narcotráfico; (ii) las formas de organización paramilitar y la dinámica del conflicto interno en Colombia; y (iii) la ausencia del Estado o el proceso de (in)visibilización de las víctimas en un contexto de opinión pública y participación política más amplio. Así pues, la aplicación del concepto, que gira alrededor de la pregunta de investigación, permite plantear interrogantes que relacionan y cuestionan cada uno de los puntos ya mencionados, puesto que incluye en términos explícitos el tema del sufrimiento de las víctimas y su proceso

\footnotetext{
${ }^{4}$ Dado que lo que está sujeto a la amenaza no es la capacidad de hablar solo de un individuo sino también de una comunidad a la cual pertenece el individuo, es preciso resaltar el carácter plural y singular de los daños y de los sufrimientos de los habitantes de la población. Por eso, advierto que es necesario tener en cuenta que no todas las experiencias ni todos los sufrimientos son los mismos. En ocasiones las magnitudes del daño pueden llegar a ser descomunales y, en otros casos, pueden no ser tan significativos, quiero decir, pueden no ser tan trágicos o nefastos.
} 
de reconciliación frente a la(s) figura(s) del (o de los) victimario(s) dentro de un proyecto jurídico de tránsito hacia la paz. En suma, el diferendo permite dimensionar la magnitud del agravio del que fueron (y han sido) víctimas los habitantes de El Placer, ya que permite precisar en términos concretos la manera en la que les fue suprimida y/o destruida su capacidad y su derecho de expresión.

\section{La paradoja política}

No es un secreto que a lo largo del siglo XX, y principios del XXI, el conflicto armado en Colombia ha producido una serie de crímenes atroces que ante la comunidad internacional de derechos humanos han sido calificados bajo el rótulo de "lesa humanidad", a los que se asocian formas de tortura (concebida comúnmente como el ejercicio de violencia que busca producir el mayor dolor posible a su víctima a fin de prolongar su muerte), masacre (concebida como el ejercicio indiscriminado y deliberado de violencia sobre todo tipo de personas) y genocidio (definido este como el asesinato masivo de comunidades enteras). Sin embargo, en este sentido, tampoco es un secreto que el impacto generado por dichos crímenes no ha sido ajeno al afán de reconstrucción y reparación del sufrimiento de las víctimas del conflicto en términos del derecho. De hecho, actualmente las políticas de inclusión y los procesos de justicia transicional buscan el reconocimiento de los derechos primordiales de comunidades minoritarias que han sido víctimas de desplazamiento forzado o de cualquier forma de daño, sea físico, moral o simbólico.

En líneas muy generales, el propósito de estos procesos jurídicos es privilegiar la exigencia de la reconciliación, junto con el reconocimiento de los derechos fundamentales de las comunidades, por medio del consenso y de la cooperación institucional que vincula a las víctimas, al gobierno local de la región y, desde luego, a los victimarios ${ }^{5}$; todo ello enmarcado, desde luego, dentro de un sistema de participación democrática que facilite las posibilidades de la reparación del daño en términos del derecho, bien sea por vía de amnistía o indulto ${ }^{6}$.

\footnotetext{
${ }^{5}$ Dentro de estos casos, se pueden encontrar proyectos regionales como el de Marquetalia $100 \%$ legal, o también el proyecto de paz local de Samaniego. Para una descripción juiciosa del caso véase De Gamboa (2010). Esto por un lado. Pero para respaldar y sustentar el presente argumento me gustaría retomar una pregunta que han dejado planteada Laly Catalina Peralta y Jorge Luis Lázaro en el capítulo "Marquetalia 100\% Legal. Una Experiencia de Erradicación Manual de Cultivos llícitos" y que, a mi juicio, resulta esclarecedora en el presente caso. A saber, "¿una política como Marquetalia 100\% legal funcionaria por ejemplo en municipios de zonas de colonización, como el Putumayo, donde el origen del campesinado es diverso y por ende es difícil la cohesión cultural, y dónde la producción de ilícitos y las expresiones del conflicto armado son de larga data?" (2010, p. 239)

${ }^{6}$ Después de impartida la Ley de Justicia y Paz (2005), y con motivo de los procesos de desmovilización (2006) promovidos por la presidencia de Álvaro Uribe Vélez, fue creada la Comisión Nacional de Reparación y Reconciliación (CNRR) con el encargo de acompañar a las víctimas en sus demandas y testimonios. Por primera vez en el país, se abría la puerta
} 
No obstante, lastimosamente las clausulas estipuladas a propósito de la igualdad o la garantía de la reconciliación y la calidad de la participación democrática de las minorías, muchas veces son insuficientes al momento de ofrecer soluciones efectivas frente a las circunstancias reales del daño y del sufrimiento de las víctimas. Si bien el apoyo institucional ofrece ciertas garantías a su favor (que es preciso y valioso reconocer), curiosamente al mismo tiempo niegan el escenario histórico del problema, debido a que se concentran en la elaboración apresurada de estrategias para poner fin a la guerra, como ocurrió con los procesos de desmovilización durante el gobierno de Álvaro Uribe, pero sin prever que los crímenes muchas veces permanecen impunes porque no se contemplan las circunstancias reales que lo desataron. Y el mayor inconveniente con esto es que, aunque bien intencionadas, las posibilidades de inclusión y de participación política animan un ejercicio de perdón y reconciliación amparado en leyes que no tienen en cuenta la magnitud de un daño que, como diría Derrida (2007), resulta imperdonable.

Por otro lado, en la larga historia de la violencia en Colombia, los grupos armados se han caracterizado por adoptar una serie de códigos y de prácticas sociales por fuera de la ley que se vuelven determinantes en el momento de la toma y del control de alguna población. Por lo general, estos grupos adoptan un modus operandi según el cual los patrones de conducta intensifican los mandos de la autoridad política, la producción del crimen, la administración económica y las reglas de convivencia social. A pesar de que los repertorios y las estrategias no son siempre los mismos (sino que han variado según la guerra y sus territorialidades, según los motivos ideológicos y las falencias del Estado), es bajo estos tres ejes -político, económico y militar- que durante casi dos décadas (si no más) se ha perpetuado el conflicto entre la guerrilla y las autodefensas. En este orden de ideas, como bien lo ha señalado Adolfo Chaparro, "se dice que tanto las autodefensa como la guerrilla han establecido una suerte de paraestado, esto es, formas de poder local que generan redes de pertenencia, de sujeción y de organización de las regiones bajo su dominio, las cuales, finalmente, permiten que los individuos mantengan unas ciertas reglas del funcionamiento económico y unas [ciertas] normas de convivencia social" (2009, p. 192). Después de todo, es justamente dentro de este doble panorama o dentro de esta duplicidad del problema, de

para el ejercicio narrativo del testimonio de las víctimas del conflicto armado. Y con motivo de los debates que se desarrollaron en el Congreso sobre el tratamiento que debía dar el Estado frente a los crímenes de lesa humanidad cometidos por los paramilitares, se abre también el debate sobre los nexos entre la parapolítica y el gobierno estatal (2007). Ahí es cuando, en Colombia, viene a aparecer el problema jurídico de la memoria, del perdón y la reconciliación, dentro del modelo de "verdad, justicia y reparación". En suma, en este contexto se abre el problema de la toma de decisiones en materia de amnistía y/o indulto, a fin de evadir litigios y producir soluciones rápidas y efectivas. Estos datos son extraídos del artículo de Adolfo Chaparro sobre justicia transicional y el tema de las AUC que se cita en este ensayo, y que el lector puede encontrar en el libro Génesis y transformaciones del Estado Nación en Colombia. 
un lado político y del otro paraestatal, que las víctimas han terminado sufriendo daños irreparables.

Si bien Héctor Galindo, Jorge Restrepo y Fabio Sánchez han tratado de darle un enfoque institucionalista al tema del conflicto armado en Colombia, que, para ellos, viene a ser consecuencia de la pobreza que impera en gran parte de la población colombiana, difieren en varios aspectos de la tesis de Chaparro. A mi juicio, el punto más interesante en el que difieren es que, de un lado, ellos defienden una tesis que, sin ánimo de ser peyorativo, constituye una verdad de perogrullo, de por sí evidente, aunque no por eso irrelevante. Con esto, quiero decir que, por ejemplo, todo el problema que proponen en el artículo Conflicto y pobreza en Colombia: un enfoque institucionalista (2009) se basa en argumentos que justifican por qué la pobreza ha sido determinante en la constitución del conflicto armado en Colombia. Y aunque la tesis tiene una validez indudable, la cuestión es que desconocen otros temas igualmente importantes, como, por ejemplo, la dinámica del conflicto interno del país... Sin embargo, por el momento seamos justos con la actual discusión, ya que es necesario reconocer que este no es único eje temático ni es el objetivo principal del artículo que escriben Galindo, Restrepo y Sánchez. Pues, pese a las diferencias, encuentro en el artículo una coincidencia fundamental con la tesis de Chaparro, a saber: el problema del conflicto se basa fundamentalmente en las fallas o en las falencias institucionales del Estado de Derecho.

Así también, una tesis similar (o supongo que se trata de una tesis ligada a la anterior) defiende Jorge Restrepo en otro de sus artículos titulado Análisis económico del conflicto interno (2009). Pero si bien en este caso Restrepo sí reconoce la complejidad estructural de la dinámica y de la organización del conflicto interno en Colombia, le sigue adjudicando una carga económica casi que total al tema de la organización subversiva, o bien al problema de la pobreza y la incidencia del narcotráfico en la economía colombiana. Teóricamente esta tesis puede darle fuerza y consistencia a la noción de "economía de la guerra" que mencionamos anteriormente, pero en realidad el texto al que me refiero no tematiza la configuración de formas de subjetivación y, sobre todo, no alude a la constitución de gobiernos paraestatales que producen diversos mecanismos de sujeción. Y el inconveniente es que este tipo de tratamiento del tema del conflicto armado en Colombia aún sigue siendo muy heredero de la tesis económica y política que defiende y desarrolla Marco Palacios en el libro Entre legitimidad y violencia (1875-1994) (1995).

Aun así, hay que ser cuidadosos con los términos de la discusión. Porque con esto no quiero decir que en ninguno de los textos comentados no se trabajen temas coyunturales en términos sociales, políticos y económicos. Por supuesto, con esto tampoco quiero desconocer la relevancia de las investigaciones que actualmente se están haciendo entorno al problema político del conflicto y de las víctimas. Del 
mismo modo, mi intención no es decir que Marco Palacios no se ha ocupado de trabajar con sumo cuidado el problema del nacimiento de los grupos insurgentes en Colombia, el desarrollo económico del narcotráfico y sus posteriores nexos con dichos grupos. Antes bien, ambos temas -el político y el económico- constituyen ejes fundamentales del presente ensayo. Pero el punto fundamental es que no se ha profundizado en el tema de la justicia transicional en términos jurídicos (como sí lo ha venido haciendo Camila de Gamboa, por ejemplo) y, para Chaparro, es allí precisamente que se muestra con claridad la paradoja jurídico-política del contexto actual colombiano. Así que, visto teóricamente, si bien el propósito de la justicia transicional es inclusivo dentro de un proyecto político, económico y social, en los casos concretos de las víctimas encontramos que, aunque los modelos de la guerra no siempre se replican ni mucho menos se teorizan de la misma manera, es en esta lógica paraestatal que se configuran redes de sujeción que han terminado por modificar, desconocer y por destruir la capacidad y el derecho de hablar (sobre lo vivido) y de callar (sobre lo visto) de un individuo y/o de un colectivo que vive, paradójicamente, en medio de intereses políticos y económicos inscritos en zonas de conflicto armado, dado que sencillamente están obligados a regirse por sus mecanismos de gobierno y de sujeción. Y, al final, esta no es más que una forma teórica de mostrar el dilema jurídico que expresa el diferendo.

\section{Los testimonios}

Después de sostener una lucha de casi tres años con el Frente 48 de la guerrilla, el Bloque Sur del Putumayo de las AUC finalmente logra establecer un control sobre el territorio político, económico y social de la población El Placer (CNMH, 2012, p. 130). Durante este tiempo, y debido a los nexos que el Frente 48 había construido con la comunidad, se fue configurando una lógica paramilitar en la que hombres y mujeres terminan siendo señalados como 'colaboradores' de la guerrilla. Así, las autodefensas desarrollan una inteligencia operativa que les permite identificar a civiles y a campesinos (indistintamente) como presuntos enemigos dentro de su mismo territorio. Y puesto que para las AUC es preciso erradicar cualquier tipo de influencia guerrillera de la zona, no tienen ningún inconveniente en ejercer la fuerza militar para crear un ambiente completamente hostil dentro de la comunidad.

Ahora bien, en este contexto, el presente apartado tiene la pretensión de hacer un pequeño análisis de caso basado en la recopilación de los testimonios de las víctimas. En ese sentido, enfoca dos problemas fundamentales: (i) la configuración y constitución del estereotipo "ser enemigo" dentro de la lógica paramilitar ${ }^{7}$, y

\footnotetext{
${ }_{7}$ Vale la pena recordar que en todos los escenarios del conflicto colombiano los modelos de represión no eran de la misma naturaleza. En este caso, me limito a ofrecer un panorama de la situación de El Placer, tratando de analizar sus alcances y sus consecuencias en un contexto reducido, dentro del cual los testimonios son el material indispensable de trabajo.
} 
(ii) la función o el rol que las mujeres desempeñan dentro de dicho gobierno paraestatal. El objetivo es describir la situación antagónica que vive la población y, en consecuencia, analizar la transformación de sus condiciones de vida.

\subsection{Ser enemigo en el imaginario de las autodefensas}

Además de que ya lo hemos dicho, resulta más o menos claro por qué desde el principio la población se convierte en el enemigo potencial de los paramilitares. Sin embargo, procuremos analizar las consecuencias de esto. Así pues, diremos que, de acuerdo con la lógica del ejercicio paramilitar, se implementa un sistema de identificación con base en "una serie de estereotipos y mecanismos [que, aunque mal fundados, sirven] para definir quién [es] "colaborador" [de la guerrilla y] para identificar al supuesto enemigo" (CNMH, 2012, p. 131). Después de todo, dicha estrategia de dominio se justifica por la lucha entre dos bandos militares. De ahí que, dados los mecanismos de identificación paramilitares, desde el inicio su tipo gobierno contiene los matices de un fascismo regional. Así que, guardando las proporciones y las diferencias, me atrevo a decir que, por momentos, el municipio de El Placer adquiere los tintes de un pequeño Lager de la época del holocausto, donde, como bien lo dice Primo Levi en Si esto es un hombre, el hombre no pretende más que la "destrucción de un hombre" (2005, p. 47). Y, en efecto, en este caso se trata de la destrucción del prójimo, del vecino, del próximo, o bien de la figura del otro:

Es que cuando llegaron los paramilitares a usted lo mataban por el hecho de
ser campesino y porque de pronto, por allá, cuando bajaba esa gente usted
le ofrecía un vaso de agua, con eso ya era suficiente para que dijeran que
usted era guerrillero y los paramilitares lo mataban. Perdimos mucho líder
bueno, familias sanas, totalmente sanas, que a uno le duele con el corazón,
gente que era como de la familia de uno (CNMH, 2012, p. 132).

Veamos el caso con detenimiento. Es evidente que las prácticas paramilitares devienen procesos de 'limpieza' de acuerdo con lo que nos dice el testimonio. De modo que familias inocentes, sin ningún lazo con la guerrilla, son asesinadas a fin de prevenir cualquier tipo influencia en la zona. En este sentido, los paramilitares disponen de un canon que, además de aplicarse indiscriminadamente sobre las personas de las que se tiene sospecha ${ }^{8}$, les sirve de código de identificación con el que pueden marcar al campesino de una vez por todas para destruirlo. O mejor, como bien lo señala el informe, "parte de las labores paramilitares

\footnotetext{
${ }^{8}$ En vez de tomar el término como concepto, en este caso la sospecha se interpreta sencillamente como una especie de afección colectiva que predispone a las autodefensas frente a los posibles guerrilleros, o bien frente a los presuntos enemigos. Sin duda, la sospecha parece ser un móvil que opera dentro de la lógica guerrera que está en juego. Por eso mismo la nota aclaratoria.
} 
en El Placer se concentraron en definir qué civil era 'propiamente guerrillero'", así que "particulares signos y atributos corporales fueron motivos de estigma, determinadas marcas en el cuerpo, formas de vestir, de caminar" $y$ "de ser fueron utilizadas como evidencia que permitía concluir el vínculo de la población con las FARC" (CNMH, 2012, p. 139). Al final, las personas podían ser señaladas simplemente por su fenotipo y por su indumentaria campesina. Las manos, la ropa, los gestos, el habla, ciertos acentos, ciertos ademanes, todos esos atributos podían ser motivo de sospecha, si bien, como se nota, se trata de un criterio de selección completamente ambiguo.

A continuación se exponen dos testimonios. El primero, de una mujer del pueblo cuyo esposo debía atravesar los retenes paramilitares y era sometido a esas pruebas de identificación. El segundo, de alias 'Pipa', comandante paramilitar, que describe cómo identificar a sus rivales:

A los hombres les miraban las manos a ver si eran trabajadores, porque los guerros tenían que tener las manos ampolladas y todo eso, reventadas. Revisaban los hombros a ver si tenían bien marcados los hombros de cargar los maletines. O si tenía alguna cicatriz les ponían problema porque decían que la guerrilla tenía cicatrices (CNMH, 2012, pp. 140-141).

Al guerrillero se le distingue por la forma de vestir [...] Digamos con camisa larga. De pronto en la forma de ellos, la mirada. En la forma de colocarse el pantalón, ellos utilizan el pantalón bien esta parte arriba [la de la cintura]. Todo eso uno se detalla. La mirada de ellos, que ellos son todos como pispiretos, ellos andan a toda hora como pendientes. Todo militar se conoce por eso, porque uno está metido en el cuento, en el combate, en la guerra, entonces suena cualquier tote o algo y uno [se sobresalta]. Entonces uno ya conoce 'ese es militar o alguna cosa'. O en la forma de hablar [...] En la forma de hablar de pronto se puede caer, porque 'Erre, copiado'. Entonces si cualquiera los marcaba, iah!, que 'erre, copiado', ese tiene que ser de algún lado: o es de nosotros, o es policía, o es del Ejército o es guerrillero (CNMH, 2012, pp. 143-144).

Desde cierta perspectiva, ambos testimonios ofrecen una descripción paradójica del asunto. Rápidamente, uno podría decir que cualquiera podía ser el enemigo, quiero decir, cualquiera con maletín, con las manos maltratadas, con gestos y ademanes "sospechosos". Pero si uno se pregunta en realidad 'iqué significa ser sospechoso?' no es difícil notar que efectivamente no hay un criterio preciso para definirlo. Lo cierto es que todas esas formas de identificación están determinadas por las relaciones de poder y de decisión que enviste la figura del jefe o del empoderado paramilitar. De ahí que el único rasgo evidente para identificar al enemigo sea la expresión 'erre, copiado', como bien lo señala alias 'Pipa', pero el resto es consecuencia de la lógica arbitraria y ambivalente de esa especie de codificación militar. En últimas, no hay un canon preciso más allá del imaginario que 
el paramilitar ha construido alrededor de la figura del guerrillero, porque incluso una simple cicatriz es motivo de estigma y posteriormente de muerte. El problema justamente es que muchas veces quienes mueren son personas inocentes.

Para gran parte de la academia ya son conocidos los relatos y los testimonios de Primo Levi acerca de la situación que sufrieron los judíos en Auschwitz. Y si bien los contextos son completamente distintos, uno podría pensar que en el caso colombiano, y en este caso especial de El Placer, la forma de gobierno paraestatal de las autodefensas, hasta cierto punto, adquiere los matices de un totalitarismo indescifrable a pequeña escala, donde, como bien describe Levi en Los hundidos y los salvados, "el enemigo estaba alrededor, pero dentro también, [de manera que] el 'nosotros' perdía sus límites, [porque] los contendientes no eran [solo] dos [y] no se distinguía una frontera sino muchas y confusas" (2005, p. 498).

Así pues, en este caso, los enemigos (o los guerrilleros) no resultan claramente distinguibles de la población campesina, empezando por el hecho de que, dentro de la lógica paramilitar, ninguno de ellos es completamente inocente. De ahí que los límites que demarcan los lazos de pertenencia entre la comunidad y las autodefensas en una especie de nosotros se vuelvan confusos y hostiles, dado que la relación de poder entre ellos supone ya de por sí la existencia de un enemigo interno, es decir, la presencia de un enemigo que está próximo, que es el prójimo, que no es un extranjero y que, por tanto, se lo puede encontrar en todas partes.

En este mismo sentido, tampoco hay distinción de género en los señalamientos. Desde luego, las mujeres también son acusadas de portar la 'seña' o el rasgo que las vincula directamente con la guerrilla. Frente a ellas, sin embargo, existe el agravante de ser violadas, de ser utilizadas como trabajadoras de oficio doméstico o de ejercer la prostitución. Es decir, aunque no hay distinción de género en los señalamientos, sí hay mayor vulnerabilidad en las mujeres, dado que pueden ser violentadas de diversas formas. Fácilmente pueden pasar de ser agredidas física y sexualmente a desempeñar labores de prostitución, o pueden pasar de ser abusadas física y sexualmente a desempeñar largas jornadas en labores domésticas. En fin, debido a la lógica de gobierno se producen daños mayores sobre el rol de las mujeres. Más adelante me centraré en el testimonio de algunas. Por el momento, quisiera resaltar la ambigüedad del reconocimiento y la hostilidad en la que vive la población durante la época, dada la "definición" de la figura del enemigo.

Lo cierto es que así como se despliega todo un dispositivo de control político, militar y económico sobre la comunidad, asimismo se cometen atrocidades ${ }^{9}$ en contra de la integridad física y moral de los hombres y de las mujeres que, dentro

\footnotetext{
${ }_{9}^{9}$ A propósito de cómo estoy entendiendo el tema de la atrocidad, el lector puede encontrar una perspectiva interesante en las ideas de María Pía Lara, donde concentra su atención en las acciones que producen daños físicos y morales sobre diferentes grupos humanos. Véase De Gamboa \& Uribe (2012).
} 
del imaginario de las AUC, son calificados indiscriminadamente como enemigos potenciales. Miremos un testimonio en el que, ahora una mujer, describe cómo tuvo que someterse a pruebas de identificación en retenes paramilitares:

Yo tenía una patrona que vivía aquí en el centro. Y con ella un día íbamos a las Brisas en una camioneta y por allá nos pararon, nos bajaron, nos requisaron. A mí me dijeron que me iban a dejar que porque yo tenía cara de guerrillera, que yo era partidaria de la guerrilla. Eso me levantaron la blusa, me levantaron la camiseta, me bajaron el pantalón, me revisaron aquí [el hombro] a ver si yo tenía señales de cuando cargan el morral, las maletas. A ver si yo tenía la boca ajada. No me encontraron nada, pero allá me tuvieron con la patrona como una hora. Nos tocó quedarnos ahí porque yo no había llevado cédula. Me buscaban en los libros, preguntaban en el radio. Dijo mi patrona: "Por esta mujer y por mí le pueden preguntar a todo el pueblo porque todo el pueblo nos conoce. Ella es una muchacha que viene de Nariño, ella es empleada mía y viene siendo como una hija mía". A ella no la requisaron tanto como a mí, es que yo iba con una sudadera negra y con botas negras y ese era el problema que me montaron a mí... Ella iba en chanclitas y yo con botas. Uno de esos señores dijo: "A esas dos viejas pásenmelas para acá para ponerlas a cocinar. Necesito que me haga el almuerzo". Entonces yo le contesté: "Yo no soy empleada suya". Dijo: iAg!, vos sos como alteradita, como arrechita. Vos sos como guerrillera" (CNMH, 2012, pp. 144-145).

En este caso, las señas son casi de la misma naturaleza que son buscadas en el cuerpo de los hombres. El hecho de llevar puesta una sudadera negra, usar botas de caucho y tener un "temperamento fuerte", es un signo que la vincula automáticamente con un nexo guerrillero; además, dado que no trae sus documentos a la mano, es más fácil tildarla como enemiga. Más aún: lo que resulta impactante de todo esto es que, una vez hombres y mujeres son identificados como enemigos, se les asesina inmediatamente, y sus cuerpos, ya muertos, sirven de vehículo para transmitir un mensaje de intimidación sobre la población (CNMH, 2012, p. 150). Es decir, una vez las personas han sido asesinadas, los cuerpos son exhibidos en los espacios públicos, a fin de demostrar una especie de fuerza y de poderío armado de las autodefensas. Así relata su experiencia una mujer del pueblo:

A esa gente no le importaba matar por acá en el centro, maltratar a la gente por acá. Los niños miraban todas las cosas. Entonces cuando cogieron a un guerrillero y lo llevaron en una camioneta desde la parte parroquial hasta el cementerio, aceleraban y de una frenaban para que se cayera. Como él iba en la parte de atrás de la camioneta, amarrado, lo tenían de aquí para allá y de allá para acá. En una de esas como que el guerrillero cogió impulso y tumbó a otro paramilitar de la camioneta, eso fue en todo el centro, entonces lo cogieron, lo bajaron ahí en el centro y lo cogieron a punta de machete. Imagínese toda la gente mirando, no les importaba que había niños mirando. Tocó venir donde el padre, con todo el miedo porque 
hasta al padre le dio miedo de que le fueran a hacer algo. El padre Nelson salió que por favor que si lo iban a matar de una vez se lo llevaran, pero que no hicieran ver eso tanto en el centro $(\mathrm{CNMH}, 2012$, p. 152).

Vemos, pues, que el objetivo paramilitar básicamente es infundir un sentimiento de terror sobre la población a través de medios/mensajes que son los cuerpos ya muertos. Como se puede leer en el testimonio, a pesar de las peticiones, cada vez aumentan las exhibiciones de los cuerpos torturados y masacrados, como si en realidad los perpetradores gozaran con el daño y con el miedo que infunden sobre la población. Y, asimismo, hay otras formas de intimidación que refuerzan estos afectos, como el desalojo y la desaparición forzada, en los que o bien se les desplaza a los sospechosos del territorio, o bien se les asesina clandestinamente. Así pues, como es de esperar, la mayor consecuencia de todo esto es que en la comunidad se despierte un sentimiento de peligro constante que termina fragmentando significativamente su identidad colectiva y su sentido de moralidad.

El pensamiento de Emmanuel Levinas es reconocido por su empeño en trabajar la singularidad de la alteridad y, al mismo tiempo, por explorar la relación más primordial que existe entre los hombres, el mundo y los otros. Para ello, ha elaborado una sofisticada crítica a la fenomenología, a fin de poner en evidencia que la relación más fundamental del hombre no es con las cosas en el mundo, como lo cree Heidegger, sino que es con el otro, con el prójimo, pues la existencia de este prójimo remite, a su vez, a una singularidad completamente inaprehensible, única, insustituible, sagrada, si se quiere, en la que yo mismo puedo reconocer mi propia alteridad como igualmente singular e insustituible, pero en relación asimétrica con el otro, dado que entre ambos se constituyen distintos modos de vida. En este orden de ideas, "la singularidad insustituible del yo remite a su vida" (Levinas, 2001, p. 40) y, en consecuencia, la vida deviene un aspecto singular e insustituible.

Pues bien, con base en esta idea levinasiana, se puede inferir una tesis preliminar, según la cual dentro de la lógica paramilitar hay un ejercicio sistemático de destrucción del aspecto insustituible y sagrado de la vida de los otros.

Al final, el punto es que debido a la ejecución del mecanismo de gobierno, los paramilitares terminan por fracturar el imaginario simbólico, moral y espacial de la población. De hecho, como bien lo ha señalado el informe, en los testimonios se muestra discursivamente cómo los actores armados obligan a que los habitantes modifiquen los trayectos o caminos que conducen a la Iglesia, a la Plaza de Mercado, al Cementerio, a la Escuela del pueblo, entre otros lugares. Para la comunidad, estos espacios están cargados de una fuerza simbólica, o por seguir la idea de Levinas, están cargados de una sacralidad insustituible que termina escindido. Además, en los testimonios también se reconstruye la forma cómo los paramilitares usan el Edificio de la plaza central para convertirlo en un espacio destinado a castigar 
y asesinar a los presuntos enemigos. En suma: las autodefensas cifran el espacio de tal manera que fragmentan negativamente el imaginario simbólico, sagrado y geográfico de la comunidad. Por eso es que también destruyen, quebrantan y segregan el aspecto singular, insustituible y sagrado de la vida del prójimo en el pueblo. La verdad es que durante este periodo la población vive con el peso de la amenaza constante, dentro del cual el enemigo es identificado, repito, de acuerdo con los criterios ambiguos del gobierno paramilitar. Así, los habitantes quedan desprovistos de seguridad civil, puesto que, en este caso, es evidente que tampoco tienen el poder de decisión como para incidir en la organización política, económica y social, ni mucho menos preventiva de la comunidad. Incluso, el único medio de supervivencia en muchos casos es el silencio, la clandestinidad...

En síntesis: llegados a este punto de la discusión es que toma forma y adquiere consistencia la tesis del diferendo. Así que, siendo rigurosos con el concepto, diremos que, en principio, la comunidad queda no solo sujeta, sino expuesta tanto a la amenaza de hablar o de callarse en contra de los paramilitares, como a la amenaza de hablar o de callarse a favor de los guerrilleros. En perspectiva, ello plantea un problema doble similar al que plantea Chaparro en su tesis. Por lo tanto, si articulamos ambas tesis al mismo tiempo, podemos concluir por ahora lo siguiente: la aplicación del concepto denuncia el proceso de violencia moral y discursiva que sufre la comunidad de El Placer, ya que dicha imposibilidad de expresión es consecuencia de los ejercicios de perpetración que persisten sobre los habitantes. Igualmente, el diferendo ilustra esa paradoja jurídica y política según la cual la población se ubica en un entre dos: entre las leyes de seguridad (ausentes) del Estado y entre la normatividad (presente) del Paraestado. En consecuencia: el diferendo, al menos por ahora, nos permite prestar atención a aquellos escenarios en los que se le impide a una víctima denunciar una sinrazón porque justamente carece de los medios necesarios y adecuados para hacerla visible (1999, p. 20).

\subsection{Ser mujer decente 0 indecente en un ambiente hostil}

Recapitulando: durante la ocupación en el municipio de El Placer, los paramilitares despliegan normas de comportamiento y labores que literalmente establecen nuevas condiciones sobre las relaciones sociales y afectivas de la comunidad. En esa lógica, el diferendo hace hincapié en la subordinación de la capacidad expresiva de los habitantes y señala las consecuencias de la forma como someten una heterogeneidad de discursos (con diversos fines comunitarios) a un solo fin (el interés económico y militar del gobierno paramilitar). Así, de acuerdo con Lyotard, los fines comunes "permanecen descuidados, olvidados, rechazados" (1999, p. 159). 
Dicho esto, me parece ahora relevante detenernos en el análisis del rol de la mujer dentro de dicha lógica de gobierno. En este sentido, una entrada que considero pertinente a este problema es precisamente la clasificación enunciativa de los paramilitares que, en últimas, es definida en términos de mujeres decentes e indecentes. En términos generales, opino que la aplicación del diferendo, al menos en un segundo momento, ilustra la magnitud del daño de las víctimas cuando se tiene en cuenta el desarrollo del negocio de la prostitución, siempre y cuando se reconozca que esta forma de explotación económica de la mujer es otra expresión de la economía de la guerra y de la organización política de las autodefensas.

Me permito citar, entonces, lo dicho en el informe a fin de poner sobre la mesa los elementos que, posteriormente, se discutirán alrededor del problema:

[Para los paramilitares] la mujer decente debía cumplir con todos los atributos de la buena hija, esposa, madre y buen ejemplo para la comunidad. Por el contrario, la mujer indecente era destituida de estos atributos, Ilamándola "prostituta", "paraquera", "recorrida", entre otras. Para ello se desplegó un sistema punitivo en que las mujeres indecentes eran castigadas en público y de una manera particular. Por otra parte, las decentes ocupaban una situación ambivalente sobre cómo actuar, de quién poder enamorarse y qué decisiones tomar para no ser "despreciadas" (CNMH, 2012, p. 173-4).

Ahora, si el calificativo indecente pretende demarcar una frontera 'definitiva' en la labor cotidiana de la mujer, sospecho que esto puede relativizarse, una vez destaquemos la dinámica y la organización del negocio de la prostitución, puesto que allí se muestra claramente el contraste que existe entre la mujer decente e indecente. De hecho, trazar esta distinción solo tiene sentido dentro del imaginario del jefe o del grupo paramilitar. Porque a pesar de que el negocio de la prostitución en apariencia es un mecanismo para prevenir casos de abuso sexual en contra de las mujeres, paradójicamente esto ya supone otra serie de abusos previos sobre su condición. Así que, si bien las 'prostitutas' desempeñan una labor importante dentro de la organización armada, dado que son mujeres que satisfacen los deseos y las necesidades sexuales de los soldados, ellas también son o, al menos, han sido objeto de castigos y de sanciones públicas, en ocasiones porque contraen algún tipo de enfermedad, o porque desvirtúan la moral de la comunidad, o bien porque simplemente no actúan de acuerdo a la reglamentación de los actores armados, o bien porque finalmente han sido violadas y/o asesinadas.

A continuación se presenta un testimonio de alias 'Pipa', donde le justifica a la 'abuela Noemí', cacica y autoridad tradicional del pueblo, por qué el negocio de la prostitución es una decisión 'política' con efectos positivos dentro de la población: 


\begin{abstract}
Cuando la abuela Noemí nos comentó [...] que ese era un pueblo pequeño y que tanta sirvengüencería que había ahí, tanto bar. Entonces ya nosotros le dijimos: "Vea, abuela, lo que pasa es que nosotros no queremos de pronto ir a generarle problemas a la población, porque hay mucho pelado de la organización que no tiene su mujer y quiere satisfacer sus deseos, entonces ya se van a meter de pronto con la mujer del señor o a irrespetar la mujer del señor o a querer mirar a las muchachas, a seducirlas. Entonces para que no exista ese problema yo creo que es mejor que existan las trabajadoras sexuales para que de pronto no vaya a haber violaciones, todo eso se puede dar". Entonces ya ella nos entendió en ese sentido, pero a ella no le gustaba. Ella quería como que nosotros acabáramos con eso (CNMH, 2012, pp. 175-176).
\end{abstract}

A propósito del testimonio, no resulta del todo desacertado recordar que la comunidad resguarda valores tradicionales y religiosos en los que se respeta la integridad física y moral de sus habitantes, y rechazan enfáticamente cualquier tipo de práctica inmoral. En esto coincido completamente con lo que dice María Pía Lara: "Cada vez que observamos un ejemplo de cómo se utiliza la violación como un arma de guerra, podemos comprender que este tipo de crímenes ocurren en lugares en donde existen valores simbólicos y culturales como la castidad, la pureza, la fidelidad y elementos diferenciales entre las identidades étnicas" (2012, p. 156). Desde luego, la violación en este caso opera como un arma de guerra. Por eso decíamos que las autodefensas causan daños morales que han terminado por fragmentar la identidad simbólica de la comunidad. Y lo interesante es que con este caso se específica el daño sobre la mujer. Además, las AUC imponen normas de convivencia social que la comunidad claramente no contempla dentro de sus costumbres. De ahí que proponga como ejemplar el caso del negocio de la prostitución, aun cuando alias 'Pipa' diga que con esto se procura evitar futuras perpetraciones sobre las mujeres. Pues el problema es que, al aprobar el funcionamiento de la prostitución, el individuo/comunidad termina modificando radicalmente sus propios valores morales. Y como los habitantes carecen del poder suficiente para incidir en ese tipo de decisiones "políticas", de haber resistencia, esto puede conllevar a consecuencias nefastas sobre las propias mujeres (violación, asesinato, etcétera). Entonces vemos que en verdad la supuesta prevención de tales abusos ya supone otra serie de daños previos sobre su condición, porque si lo impiden es contraproducente, pero si lo aceptan también. $\mathrm{O}$, dicho en pocas palabras, los paramilitares excluyen, rechazan, ignoran e incluso destruyen la capacidad de decisión, digamos, autónoma de cada uno de los individuos, a consecuencia de imponer formas de convivencia social y de producción económica sobre la comunidad.

En esta lógica administrativa de los prostíbulos, por ejemplo, se crean puestos de control y programas de salud para garantizar las condiciones de salubridad del trabajo de las mujeres indecentes. Pero, en sentido estricto, ellas son víctimas de una paradoja. La paradoja consiste básicamente en que todo este plan de salubridad y de garantías termina produciendo otra serie de estigmas, por el 
simple hecho de que la prostitución opera en contravía de las tradiciones de la comunidad. Del mismo modo, otro inconveniente se produce cuando los controles de salud se desarrollan en público, puesto que no hay manera de evitar los señalamientos de la población sobre las mujeres que son identificadas como trabajadoras sexuales; sencillamente son obligadas a desempeñar esas labores, así que su situación ya es completamente antagónica frente a la comunidad y frente a sus costumbres.

\section{Un ejemplo puntual:}

Es el caso de una niña que a los doce años fue obligada, bajo amenaza del comandante 'Coco', a tener relaciones sexuales con distintos actores armados: "Mi mamá les decía que me respeten que yo era una niña de casa $[. .$.$] le dijeron que yo era más vivida que cualquiera, [...] que a mí$ me comían en todos los potreros hasta cinco paracos. Mi mamá regresó llorando y me dijo: "iJum!, si acá lo que hemos tenido es una prostituta que se revuelca con todos, ya mismo te vas de esta casa porque yo no puedo vivir con la prostitución" (CNMH, 2012, pp. 195-196).

Este caso justifica lo que acabamos de mencionar. Es claro que, por un lado, la niña no puede denunciar los abusos que se le han cometido porque corre el peligro de sufrir un daño mayor: la muerte. Así también, de otro lado, también es claro y evidente que queda sellada, marcada, señalada o estigmatizada públicamente como una mujer indecente, por causa del abuso sexual del que ha sido víctima. En fin, sea como sea, este caso particular da cuenta del doble proceso de victimización de la mujer, pues la situación en la que se encuentra afecta significativamente sus relaciones tanto familiares como sociales. Así pues, ¿en qué consiste el doble proceso de victimización? Respuesta sintética: en que, por un lado, hay una victimización previa en la que no hay manera de expresar el daño que le han cometido y, por el otro, hay un proceso de victimización según el cual a la niña se le rechaza y se le excluye definitivamente tanto de la familia como de la comunidad.

Desde luego, hay mecanismos de sanción que son impuestos sobre las mujeres indecentes con el fin de regular la vida cotidiana de los prostíbulos y las labores de las demás mujeres de la comunidad ${ }^{10}$. Pero es justo en esta dinámica que la frontera entre mujer decente e indecente se vuelve confusa (del mismo modo como anteriormente se mostraba la dificultad que implica adherir la comunidad en un "nosotros" indescifrable), puesto que las situaciones, por sí mismas, son ambiguas. Después de todo, convertirse en mujer indecente resulta relativamente fácil, dado que en cualquier momento pueden ser víctimas de un abuso sexual que las liga

\footnotetext{
${ }^{10}$ Me refiero a medidas de sanción por no trabajar la jordana prevista o por haber contraído alguna enfermedad, motivos que llevaban al escarnio público, que era el modo estándar de sanción.
} 
automáticamente con el ejercicio de la prostitución. Por eso, el establecimiento de los prostíbulos, en vez de prevenir un proceso de victimización, lo duplica.

Otra cosa: en algunos casos, con el fin de evitar este tipo de perjuicios, las mujeres que han sido violadas y/o amenazadas por los actores armados optaban por guardar silencio y evadir ciertos espacios comúnmente transitados. A continuación se presentan dos testimonios: uno que describe ese miedo que produce transitar por ciertos espacios militarizados y otro que describe un caso en el que una mujer decide guardar silencio y no denunciar una violación de la cual fue víctima:

Nosotros teníamos que caminar por el centro, y las trincheras estaban aquí y
acá [señala a todos lados]. Y no había otro camino porque ellos no dejaban
pasar por otro lado, nos tocaba por obligación pasar por medio de las
trincheras. Yo ya salía todos los días con las niñas pasando por las trincheras
y todos los comentarios que decían... Que cogían a las mujeres, que las
violaban, que esto y que lo otro, y los hombres era como más riesgoso que
anden porque los cogían y los mataban. Mis hijas la una tenía 15 años, la
otra 13 y la otra como 9 años. Todos los días pasábamos las cuatro cuando
bajábamos a la escuela pero yo me devolvía. Mientras ellos estuvieron ahí
yo siempre las vine a dejar yo o el papá, hasta acá, apartado de la trinchera.
Y cuando iban a salir teníamos más o menos el horario que ellas iban a subir
y nos encontrábamos (CNMH, 2012, p. 210).

Lo primero que dije fue '[debo] contarle a mi papá', pero ya mi papá tenía tantos problemas con lo de la guerrilla y con lo de acá que no se podía ir del pueblo, que si le cuento él sería capaz de ir, poner la cara y se hace matar, porque [a] 'Coco' no [...] le importaba matar, no le importaba nada la vida de nadie $(\mathrm{CNMH}, 2012$, p. 215).

Pues bien, en el primer testimonio se muestra por qué finalmente la comunidad termina transformando su propia apreciación del espacio y del territorio. Estrictamente hablando, el territorio, incluso el agrícola, deja de pertenecerle a la comunidad. Las mujeres se vuelven más proclives al abuso sexual y los hombres, a su vez, se vuelven un blanco fácil para el asesinato, bien sea por prevenir un abuso, o por portar la "seña" guerrillera. De modo que es necesario buscar la manera de 'no provocar' a los paramilitares con algún ademán sospechoso. La consecuencia, por supuesto, es la creación de una nueva codificación del territorio dentro de la comunidad, a fin de prevenir futuros males, puesto que, de otro lado, descuidar a las niñas también puede ser motivo de una futura violación inminente.

El segundo testimonio, por su parte, sugiere una estrategia de supervivencia, o bien una estrategia que permite evitar un acto de crueldad por parte de las AUC. En este sentido, guardar silencio es una manera de evitar la victimización en dos sentidos: por un lado, previene el asesinato de un padre y, por el otro, evita la 
vergüenza de ser señalada como una mujer indecente. Ahora, si bien el testimonio no dice mucho al respecto, no es difícil inferir de allí que la mejor solución en una situación como esta es permanecer en silencio. Es más, el silencio, visto desde esta perspectiva, es un resguardo a cierto grado de integridad de la persona.

En resumen: el conjunto de estigmas que recae sobre el rol de la mujer se presenta de múltiples formas y genera un raro antagonismo sobre la situación afectiva de muchas de las mismas mujeres. Claramente, hay una alteración radical de sus modos de vida $y$, al final, el ejercicio de perpetración termina quebrantando significativamente las costumbres y los imaginarios simbólicos de la comunidad. Dicho esto, podemos extraer una segunda conclusión, según la cual el doble proceso de victimización que recae sobre las mujeres de El Placer es producto de un proyecto político que impone un reino de fines sobre los modos de vida de un colectivo con géneros discursivos completamente heterogéneos. O bien, dicho en pocas palabras: en la comunidad existe una diversidad de universos discursivos que quedan reducidos a un solo género discursivo, cuyos intereses son económicos y operan dentro la lógica de un régimen político cuya máxima expresión es la guerra.

Así, de acuerdo con Lyotard, la imposibilidad de denunciar un daño o una sinrazón "se expresa por el silencio [y] por el sufrimiento. [Y] resulta del hecho de que todos los universos de frases y todos sus eslabonamientos están o pueden estar subordinados a la única finalidad del capital" (1999, p. 197). Y, en este sentido, la figura de la víctima se produce discursivamente, dado que el modus operandi paramilitar termina por negar y destruir el universo discursivo de un colectivo para ponerlo al servicio de un capital económico y político claramente ilegal. Más aún: lo intestimoniable, en este caso, se resguarda por debajo de la dinámica de esa economía, donde lo que prima es la expresión política y militar de la guerra.

\section{La paradoja del dar cuenta de sí}

Lo hecho hasta aquí ha dejado algunas cosas en el tintero"11. Hemos visto que el diferendo nos puede dar luces sobre cómo abordar el problema de la amenaza a la que se ve sometida la población de El Placer durante la ocupación paramilitar. $\mathrm{Y}$, en consecuencia, hemos trazado así el mapa que nos permite ahora integrar el problema paraestatal con el problema jurídico-político y analizar desde este punto de vista el tema de la memoria, de la reconciliación y del perdón.

Una salvedad. Si bien hace falta una exposición sistemática del concepto, el objetivo era mostrar cómo sirve de panorama y punto de convergencia en el análisis de caso, pues su aplicación resulta del todo ilustrativa. De alguna forma,

\footnotetext{
${ }^{1}$ Como, por ejemplo, el tema y la forma en la que se educó a los niños en medio del conflicto o las tareas específicas sobre cómo reconstruir los cimientos de la comunidad después de la guerra.
} 
en el diferendo confluyen las ideas retomadas de Levi, Levinas y Lara, con las cuales se ha pretendido analizar las consecuencias del régimen paramilitar. Además, desde el principio el concepto nos ha permitido abordar el caso desde cierta perspectiva que intenta destacar el ejercicio de perpetración donde se subordina, se excluye, se silencia y se imposibilita la voluntad de pronunciarse de un individuo/colectivo en contra de un régimen de gobierno paraestatal al margen de la ley, es decir, que opera en ausencia del Estado. Pues bien, es justo aquí donde se vuelve relevante el tema de la memoria y del perdón. Así que hace falta extender el análisis sobre la falta de participación del Estado, las condiciones del departamento del Putumayo incluso antes del asentamiento del grupo paramilitar en El Placer y el proceso de victimización dentro del contexto político y democrático de la sociedad colombiana, donde los testimonios, y la misma condición humana, pasan desapercibidos dentro de un panorama de opinión pública y participación política más amplia.

La cuestión es que, una vez se reconoce que el gobierno de las autodefensas opera como un proyecto político paraestatal financiado por el narcotráfico (cuyo capital proviene de una economía de la guerra), no es difícil derivar de ahí algunas consecuencias sobre las condiciones que, a nivel democrático, impiden el reconocimiento de los vejámenes a los que fueron sometidos los diversos individuos de la comunidad. De manera que, desde este punto de vista, al menos parcialmente, queda al descubierto (i) la ausencia de participación del Estado en zonas de conflicto armado (en El Placer específicamente), (ii) las aristas de los procesos de desmovilización que se desarrollaron durante el gobierno del ex presidente Álvaro Uribe $(2006)^{12}$ y (iii) las dificultades que supone un proceso de verdad, justicia y reparación, enmarcados dentro de un proyecto de tránsito hacia la paz.

Es verdad que el contexto de la desmovilización o de la propuesta de la ley de Justicia y Paz en el 2005 contribuyó por lo menos al desarme y a la disminución de las masacres que fueron consecuencia del conflicto armado y de las políticas implementadas por el ex presidente Uribe. Sin embargo, dentro de este modelo de 'justicia, perdón y reconciliación' es probable que las diversas posibilidades narrativas de las víctimas no encuentren un espacio adecuado para la reparación del daño ni, por consiguiente, para la reconciliación con sus victimarios, dado que la mayor dificultad estriba en que "la utilidad política y moral de la posibilidad del perdón, en estos casos, es confrontarnos con las implicaciones que tiene para una sociedad el reconocimiento de lo imperdonable" (Chaparro, 2009, p. 258).

\footnotetext{
${ }_{12}$ Uno de los temas más interesantes que queda por fuera de este trabajo es el desarrollo de las políticas en contra del terrorismo implementadas por el gobierno de Álvaro Uribe, dentro de las cuales hay una declaración explícita de "hacerle la guerra al enemigo interno", apelativo con el cual se identificaban a los grupos guerrilleros. En este sentido, no estaría de más intentar articular la hipótesis del enemigo interno con la dinámica del mismo conflicto que aquí se intenta problematizar con el análisis de caso, pero, desde luego, esto sería materia de otro trabajo.
} 
Así pues, el punto neurálgico de la discusión reside en la imposibilidad de que las víctimas perdonen algo que, en principio, como bien lo menciona Derrida, resulta imperdonable. Esto no quiere decir, empero, que no se hayan hecho proyectos con el fin de producir soluciones efectivas. Uno de los trabajos más interesantes en este sentido, a mi juicio, se expone en el texto El tránsito hacia la paz: de las herramientas nacionales a las locales (2010) (libro editado por la jurista y filósofa Camila de Gamboa), donde se exponen casos de conflicto local tanto en Latinoamérica como en cierta región del África. El propósito fundamental del libro es promover y mostrar la cooperación entre los gobiernos locales, los grupos subversivos (o victimarios) y, sobre todo, las víctimas, a fin de que se integren en un proyecto jurídico y democrático de tránsito hacia la paz. Y ese, me parece, es el objetivo principal de la justicia transicional. De modo que, hasta ahora, tenemos dos polos de la discusión: uno teórico e histórico que plantea el problema en términos de una paradoja política, y otro que plantea el problema en términos de una praxis educativa que, además, promueve un ejercicio local de reconciliación y de reparación entre organizaciones legales entorno a los procesos de victimización.

No obstante, a pesar de la efectividad de algunos de los proyectos regionales, persiste el problema ético (no jurídico) de cómo perdonar aquello que resulta imperdonable y de cómo testimoniar aquello que resulta intestimoniable. Es más, siendo rigurosos con el análisis conceptual que hemos hecho sobre el caso de El Placer, el problema ya no parece ser tanto el de la reconstrucción histórica de la masacre, sino el de la propuesta conceptual, práctica y metodológica sobre cómo afrontar la situación, es decir, sobre cómo superar el daño, sin desconocer, por supuesto, el tema de cómo hacer memoria en este sentido. Pero lastimosamente, llegados a este punto, chocamos de nuevo con una paradoja que pareciera irresoluble. De cara al caso de El Placer, por ejemplo, la paradoja parece no tener solución por el hecho de que la comunidad ha vivido inmersa en una economía de la guerra, cuyo régimen les ha reprimido un medio de expresión a través del cual, se supone, podrían denunciar y restaurar, al menos dentro de los proyectos de justicia transicional, su participación democrática. Pero dado que su capacidad de expresión ha atravesado un mecanismo masivo de destrucción, resultan demasiado precarios los recursos que tienen para pronunciarse al respecto. $\mathrm{O}$ dicho en otras palabras, la paradoja reside en que si bien el modelo de justicia y tránsito hacia la paz confiaba en aquella época en los procesos de desmovilización como un medio eficiente para llegar a la paz, al mismo tiempo desconocía las posibilidades de un reconocimiento efectivo del sufrimiento de las víctimas, puesto que no contemplaba el carácter inconmensurable del daño. A propósito, ya son varios los académicos que coinciden con la idea según la cual los procesos de desmovilización han dado motivo para que los crímenes de lesa humanidad hayan quedado impunes dentro de un proyecto de reconciliación como el de Justicia y Paz (2005). 
Aún más: a esto tendríamos que añadir los daños que se cometieron sobre las zonas de producción agrícola con el proyecto del Plan Colombia ${ }^{13}$ y las formas en que el gobierno ha concertado la ley de restitución de tierras de las víctimas en términos del derecho (ya sea por vía de indulto o amnistía). No obstante, mi intención no es decir que el proyecto sea motivo de reproche. Antes bien, opino que el proyecto no supone una comprensión previa de los perjuicios cometidos a las víctimas, o por lo menos no dentro de un ámbito de opinión pública horizontal y democrática, que es el punto que quiero resaltar con el concepto del diferendo. De modo que si sumamos estas aristas al problema, no es difícil deducir de allí que, dentro del Plan Colombia y el modelo de Justicia y Paz, persiste el privilegio por un perdón y una reparación fingida y forzada en los procesos de reconciliación, debido a la incomprensión de las condiciones reales del daño de las víctimas y a la falta de garantías sobre el hecho de que tales circunstancias no se repitan, sobre todo en escenarios donde la seguridad democrática del Estado es ausente.

En otras palabras, el afán de la ley por traducir el daño de las víctimas en términos del derecho resulta contraproducente para las propias víctimas. Finalmente, como bien lo señala Giorgio Agamben (2009, p. 16-17), "el derecho no tiende en última instancia al establecimiento de la justicia. Tampoco al de la verdad. Tiende exclusivamente a la celebración del juicio, con independencia de la verdad o de la justicia"14. Aclaremos los términos de la crítica que estoy proponiendo en términos: con esto simplemente quiero decir que, aunque la comisión de verdad y de memoria histórica se comprometa con la reconstrucción de los escenarios de violencia y el problema de las víctimas, existe el problema de cómo llegar a un consenso a propósito de la verdad, el perdón y la reconciliación, sobre todo cuando los testimonios se pueden pronunciar de diversas maneras y sobre múltiples atrocidades; o, incluso, puede que ni siquiera se pronuncien, pues han sido destruidos. En este sentido, es indudable el grado de incertidumbre que plantea el concepto del diferendo en términos políticos y jurídicos. Por eso

\footnotetext{
${ }^{13}$ Me refiero al proyecto nacional que contó con el apoyo de Estados Unidos y que fue aprobado en 1999 con el fin de erradicar las zonas de cultivos ilícitos en ciertas zonas de Colombia (sobre todo en el sur, en el departamento del bajo Putumayo) por medio de fumigaciones con glifosato.

${ }^{14}$ Esta idea hay que desarrollarla un poco más detenidamente, pero al menos la mención da cuenta del asunto que me interesa señalar. Además, me parece aún más diciente su crítica al derecho por medio de un comentario que hace de El proceso de Kafka. Me permito citar en extenso: "Pocas veces se ha hecho notar que este libro, en el que la ley se presenta exclusivamente en la forma del proceso, contiene una intuición profunda sobre la naturaleza del derecho, que no es aquí tanto norma -según la opinión común- cuanto juicio y, en consecuencia, proceso. Pero si la esencia de la ley-de toda ley- es el proceso, si todo el derecho (y la moral que queda contaminada por él) es solo derecho (y moral) procesal, ejecución y transgresión, inocencia y culpabilidad, obediencia y desobediencia se confunden y pierden importancia. 'El tribunal no quiere nada de ti. Te recibe cuando vienes y te despide cuando te vas'. El fin último de la norma es la producción del juicio; pero este no se propone ni castigar, ni hacer justicia ni descubrir la verdad. El juicio es en sí mismo el fin y esto constituye su misterio, el misterio del proceso" (Agamben, 2009, p. 17).
} 
mismo, aunque el lenguaje del derecho ayude a promover soluciones jurídicas, no basta para pronunciarse sobre aquello que resulta imperdonable, pues francamente llega a término (el juicio) por vía de amnistía o indulto, de suerte, al final, no propone un reconocimiento ni una reparación de los oprimidos, como diría Walter Benjamín.

En síntesis: como vemos, la paradoja persiste y plantea un problema ético y educativo en términos de memoria y reconciliación. Pero a pesar de todo, el escenario no es del todo desalentador. Volvamos por un momento al caso. Es verdad que la situación de la comunidad está inscrita en un antagonismo aparentemente irresoluble. Sin embargo, esto no implica que no exista allí una preocupación de la comunidad por desarrollar prácticas de agrupación entre mujeres y hombres, por medio de las cuales se intenta crear mecanismos para la reparación simbólica de la memoria y del daño que sufrió la población durante esa época del régimen paramilitar. Y el único objetivo de estos mecanismos es resistir al régimen hostil que produce el conflicto. Así que, pese a las continuas perpetraciones de las autodefensas, hay una especie de disposición comunitaria por tratar de resistir al estigma y al sufrimiento. Se trata, entre otras cosas, de una voluntad que pretende cuidar de sí y del otro en virtud de las condiciones de vulnerabilidad de la población.

Por ende, la tesis del diferendo, además de que remite a un caso concreto, realmente plantea un problema dentro del cual sitúa el entre dos en el que viven las víctimas de El Placer. Por eso mismo es que mi intención es resaltar el trabajo que, después del proceso de desmovilización de las autodefensas, hizo la cacica Noemí, una mujer que durante el dominio paramilitar asumió la autoridad y la voz del pueblo con el fin de mediar entre los grupos armados y los individuos de la comunidad (CNMH, 2012, cap. 3, numeral 8 y 3). Menciono el caso porque ella fue quien, en compañía del párroco Nelson Cruz, recolectaron y recuperaron utensilios domésticos, herramientas, indumentaria, ropa y demás objetos de las personas damnificadas $(\mathrm{CNMH}, 2012$, cap. 3, numeral 8 y 4) con el fin de construir un museo que sirviera de escenario simbólico para la educación de los jóvenes y para la reconstrucción de la memoria en la región. ¿Esto qué tiene que ver con el diferendo? Respuesta: pues que además de que el diferendo nos permite referenciar o analizar los casos concretos y plantear problemas éticos en términos conceptuales, también nos permite articular la tesis que Judith Butler desarrolla en su libro Dar cuenta de sí mismo (2009), según la cual el relato o la historia narrativa de un 'yo' se asume siempre in media res: (i) entre las reglas que son impuestas por una institución o por una forma de gobierno y (ii) entre la autonomía de los individuos. Además, si se mira con atención, la articulación de ambas tesis da lugar y posibilidad a la acción de resistencia, desde luego, dependiendo del caso o de la situación. Y es en este sentido que vale la pena pensar el ejercicio narrativo de las víctimas de El Placer en términos ya no simplemente de un "yo" individual, sino en términos, digamos, de un yo-colectivo (in media res) que tiene la voluntad 
de denunciar los daños o las sinrazones de las cuales han sido víctimas, aún en el lugar de aquel individuo que ya está muerto. Y así, el caso de Noemí y de Nelson, en términos de Butler, constituye una forma mediante la cual es posible dar cuenta de sí, mientras que, en términos de Lyotard, constituye una forma mediante la cual es posible resistir al daño.

Siguiendo este orden de ideas, diremos, por tanto, que la comunidad debía seguir una serie de reglas que les privaba de su capacidad de expresión, pero que, en ciertas ocasiones, les permitieron afianzar su voluntad para cuidar de sí mismos en un ambiente hostil, y aún por medio del silencio, ya que, después de todo, el silencio constituye otra forma de acción por omisión que resguarda cierto grado de integridad personal. Al final, se trata de estrategias que permitían que la comunidad cuidase de un núcleo familiar o común en medio del conflicto armado. Lo cierto es que el silencio servía "para evitar ser tildados de 'enemigos', 'colaboradores' [y/o] 'guerrilleros'”, además, les permitía "asumir ante los armados una posición neutra, imparcial y apolítica" (CNMH, 2012, p. 292). A continuación se expone un testimonio que intenta ilustrar el punto que hemos venido discutiendo y luego comentaremos en qué consiste asumir una posición de ese tipo:

Pues cuando ellos venían aquí a preguntar que 'si usted conoce a tal', uno [respondía] 'no'. De mi parte, así yo los conociera, yo decía que no. 'No, yo no lo conozco', '¿Quién es él?', 'jumm, yo no sé' [...]. Nosotros no nos metíamos con nadie. A uno venían y le preguntaban y uno: "Humm, yo no sé, yo no sé, yo no sé' [...]. Ni a los unos ni a los otros [...]. 'Yo no sé' así [supiera]. No vi, me negaba, nunca decía nada" (CNMH, 2012, p. 293).

Una vez más: con este testimonio volvemos a justificar la tesis del diferendo y, además, podemos observar de manera clara cómo es que se aplica al análisis de caso. O digamos por qué, al final de cuentas, hace evidente una contradicción importante, pues, por un lado, resalta el sentimiento de miedo y de temor de la comunidad y, por el otro, hace hincapié en esta idea que consiste en asumir una especie de posición neutra o imparcial (entre dos), a fin de evitar futuros agravios. Así que, cuando alguien adopta una posición apolítica frente a un interrogatorio militar y guarda silencio, efectivamente, allí mismo cuida de sí, quiero decir, allí mismo reluce su silencio insustituible y sagrado que resiste al daño.

Lo importante es preguntarnos, ahora sí, qué reto presenta para "nosotros"15, como academia y como sociedad democrática colombiana, el hecho de que las víctimas se vean privadas de su propia capacidad expresiva frente a un gobierno

\footnotetext{
$\overline{15}$ Insisto poner en el entrecomillado el término "nosotros" para resaltar esa ambivalencia o esa problemática de adherencia de una cultura minoritaria a un proyecto político identitario en Colombia, dentro del cual nos adherimos normalmente en cuanto creemos pertenecer a una sociedad democrática sin prever las consecuencias o las implicaciones de esa adherencia en la vida de los otros o de las otras culturas minoritarias, civilmente no reconocidas.
} 
paraestatal, de un lado, y frente a un sistema jurídico y democrático, del otro (un sistema jurídico que, entre otras cosas, no logra ofrecer los medios adecuados para la reconciliación y para la reparación del daño). El inconveniente real, por tanto, es cómo encontrar un espacio donde el diferendo pueda ser superado, de tal manera que abra un horizonte de comprensión en el que las víctimas y la cultura democrática se enfrente con el problema real de lo imperdonable.

Para decirlo rápidamente, la paradoja jurídica y política que se ha expuesto a lo largo del ensayo francamente impide que el lenguaje del derecho haga presente el daño, por el dilema que expresa el diferendo, o bien por la situación de las víctimas. Pues, como se ha venido diciendo, existen a su base una serie de sinrazones previas que hacen difícil su denuncia en un contexto político más amplio. De otro lado, el riesgo estriba en que, una vez abierto públicamente al debate, al consenso y a la reconciliación entre las víctimas y los victimarios, el escenario histórico o las circunstancias reales del daño sean negados o invisibilizados por la celebración de un juicio jurídico (Agamben) que se resuelve por vía de amnistía o indulto. Y entonces se puede presentar un fenómeno en el que se otorgue perdón a consecuencia de que los crímenes de lesa humanidad queden impunes (que es lo que sinceramente suele suceder en el contexto colombiano). Más aún: otra consecuencia que se puede derivar de allí es que el discurso de la justicia transicional o los proyectos de tránsito hacia la paz confundan el tema de los derechos humanos, o el reconocimiento de unos mínimos democráticos válidos jurídicamente para todos los ciudadanos, con el tema de la reparación de las víctimas. Me explico: no hay duda de que para lograr un modelo eficaz de reparación, el lenguaje de los derechos humanos debe coincidir en varios aspectos con el tema de la restitución de tierras, el reconocimiento económico, la reparación simbólica y la adjudicación de responsabilidad jurídica y penal. Pero justamente la dificultad consiste en recuperar esa verdad histórica no reconocida, pero que sigue girando en torno a la memoria de un colectivo que ha sido objeto de continuas perpetraciones.

Así las cosas, me parece que es muy probable que las posibilidades de expresión de las víctimas, puesto que debe integrarse a un modelo homogéneo en términos del derecho, quede mediado por un modelo económico que interviene en la producción agrícola y en la organización política del actual gobierno neoliberal colombiano. Y, en este sentido, es muy fácil inferir de allí que las posibilidades de un perdón no se concreten, puesto que el diferendo bien puede correr el riesgo de ser traducido por el lenguaje del derecho en términos de un consenso democrático, en cuya base están implícitos los intereses de una política neoliberal. 


\section{En conclusión}

Después de la reflexión adelantada, queda abierta la pregunta sobre cómo comprender el problema de las víctimas y sobre cómo hacer memoria entorno a lo ocurrido. Pero, como ya hemos visto, el ambiente no es tan desolador. De hecho, la multiplicidad de formas y de mecanismos del cuidado de sí depende de la manera en que, dentro de una serie de normas, los habitantes logran sobrevivir en un contexto de conflicto. $Y$ aunque no resulta bastante prometedora una idea de reconciliación, por lo menos sí parece sugerente la posibilidad de una reconstrucción de la memoria colectiva en la región. De manera que las estrategias de supervivencia de las víctimas apelan a una política de resistencia frente a su propia condición de vulnerabilidad. Así, el diferendo, o bien el problema de qué y cómo recordar desde una multiplicidad de fines, puede solventarse, si bien no definitivamente, sí por lo menos parcialmente asumiendo las condiciones de las victimas desde cierta perspectiva que conserva la voluntad de cuidar de sí como comunidad. En últimas, mi impresión es que si se quiere ampliar el espectro de comprensión del modelo 'memoria, perdón, olvido y reconciliación', tendría más sentido dejar abierta la pregunta sobre cómo es que un colectivo logra superar el trauma de la guerra tratando de cuidar de sí $\varphi$

\section{REFERENCIAS}

Agamben, G. (2009). Lo que queda de Auschwitz. El archivo y el testigo. Homo Sacer III. Valencia: Edición Pre-Textos.

Butler, J. (2009). Dar cuenta de sí mismo. Buenos Aires: Amorrortu Editores.

Chaparro, A. (2009). "El discurso sobre el conflicto armado" y "Estado y justicia transicional. El caso de las AUC". En Chaparro, A. \& Galindo, C. Génesis y Transformaciones del Estado Nación en Colombia. Bogotá: Editorial Universidad del Rosario.

De Gamboa, C. (Ed) (2010). El tránsito hacia la paz: de las herramientas nacionales a las locales. Bogotá: Editorial Universidad del Rosario.

Derrida, J. (2007). "Política y Perdón". En Chaparro, A. (Ed.). Cultura Política y Perdón. Bogotá: Editorial Universidad del Rosario.

Galindo, H., Restrepo, A. Aponte, D. y Sánchez, F. (2009). “Conflicto y pobreza en Colombia". En Restrepo A. y Aponte, D. (Eds). Guerra y violencias en Colombia. Herramientas e interpretaciones. Bogotá: Editorial Pontificia Universidad Javeriana. 
Informe del Centro Nacional de Memoria Histórica (2012). El Placer. Mujeres, coca y guerra en el Bajo Putumayo. Bogotá: Publicaciones Semana.

Lara, M. P. (2012). "Reconsiderando la perspectiva sobre el mal en el paradigma de la atrocidad". En De Gamboa, C. \& Uribe, Á. (Ed.). Fuentes del mal. Bogotá: Universidad Nacional de Colombia y Universidad del Rosario.

Levi, P. (2005). Trilogía de Auschwitz. Barcelona: Ediciones Océano.

Levinas, E. (2001). Entre nosotros. Ensayos para pensar en otro. Valencia: Edición Pre-Textos.

Lyotard, J. F. (1999). La diferencia. Barcelona: Ediciones Gedisa.

Palacios, M. (1995). Entre legitimidad y violencia (1875-1994). Bogotá: Editorial Norma.

Restrepo, A. J. (2009). "Análisis económicos de conflictos internos". En Restrepo A. y Aponte, D. (Ed.). Guerra y violencias en Colombia. Herramientas e interpretaciones. Bogotá: Editorial Pontificia Universidad Javeriana. 